\title{
APROXIMACIÓN AL MULTICULTURALISMO DESDE LAS REALIDADES MULTIÉTNICAS LATINOAMERICANAS Y COLOMBIANAS
}

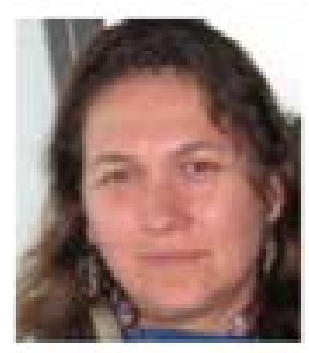

\author{
Marcela Angelina Aravena Domich \\ Universidad UMECIT, Panamá \\ domich2@yahoo.com
}

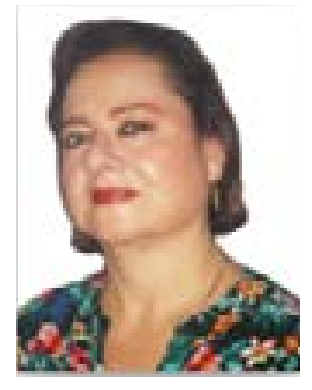

\section{María del Socorro Ramírez Giraldo Universidad UMECIT, Panamá mariramirez_co@yahoo.com}

\section{RESUMEN}

El presente artículo de reflexión, de naturaleza documental, trabaja sobre las realidades multiétnicas latinoamericanas y colombianas. Se propone una aproximación al multiculturalismo. La intención es presentar una reconceptualización de la multiculturalidad, en la que los conceptos de identidad pluralista y de multietnia. Estos últimos conceptos, entran en juego para explicar el paso del colonialismo del pasado y su pertinencia en la modernidad del presente, como un elemento fundamental del encuentro entre los pueblos, la preservación de los legados culturales, la necesaria identidad latinoamericana y colombiana y, el desarrollo de una conciencia histórica distinta, en la que emerja una visión renovada de la pluralidad como encuentro y diálogo entre los seres humanos.

Palabras clave: Multiculturalismo, pluralismo, multietnia, identidad, modernidad, colonialismo. 


\section{APPROACH TO MULTICULTURALISM FROM LATIN AMERICAN AND COLOMBIAN MULTI-ETHNIC REALITIES \\ ABSTRACT}

This documentary article proposes a reflection close to multiculturalism, it is about the Latin and Colombian multiethnic reality. It aims to reconceptualize multiculturalism in which plural identity and multiethnic groups take action to explain the entrance of the past colonialism and its appropriateness at present as a fundamental element for the meeting among people, the preservation of cultural legacy, the necessary Latin and Colombian identity and the development of different historic awareness in which emerges an upgraded vision of a diversity as a meeting and dialogue among human beings.

Key words: multiculturalism, pluralism, multiethnic, identity, modernity, colonialism

\section{INTRODUCCIÓN}

El documento presenta distintos argumentos acerca de la noción de multiculturalismo en América Latina y Colombia generando una propuesta basada en autores y en experiencias de estos países. Es necesario, como una primera aproximación a una temática de interés y de pertinencia, conocer en profundidad la raigambre sociohistórica, política y económica, de pueblos que tradicionalmente han sido marginados, excluidos y explotados. En el primer apartado, se construyen y entran en discusión tres conceptos básicos: el de multiculturalidad, pluralismo y sociedades multiétnicas.

El apartado segundo, tiene como punto de partida la contribución de Paco Gómez Nadal (2017), la cual es relevante para comprender la naturaleza de los viejos y nuevos colonialismos en el contexto de los desarrollos sociales, económicos, políticos y culturales de pueblos indígenas y afros latinoamericanos. Se despliega una tesis que, desde la realidad Colombiana contrasta los aportes del autor para comprender adecuadamente la actualidad y el destino histórico de lo que Gómez (2017) denomina pueblos "sombra". Todo esto con el fin de indigenizar la modernidad planteando una especie de retorno a los pilares fundamentales de las culturas que, hoy en día deben aprender a reconocerse y a valorarse sobre la base de sus cosmogonías, tradiciones, valores e identidades.

En último lugar, las consideraciones finales, entregan las reflexiones necesarias para que el multiculturalismo latinoamericano y colombiano, se construya a partir de las realidades multiétnicas, desarrollando una cultura fuerte y con identidad desde lo étnico, lo histórico y lo político. 


\section{TRES CONCEPTOS EN DISCUSIÓN}

\subsection{MULTICULTURALISMO}

La reflexión por el multiculturalismo en Latinoamérica, comienza por una resignificación del concepto y que ponga de relieve el contexto particular y las características propias que lo identifican. Hablar de multiculturalidad implica poner en cuestión la comprensión del sentido de lo cultural, lo multicultural y lo pluricultural. Todo ello, atravesado por el concepto de identidad, necesario para construir y constituir una cultura. Desde una mirada histórica, es necesario pensar el multiculturalismo como una construcción social y que comienza siglos atrás con la colonia.

Se debe considerar, para comenzar, el concepto de identidad, el cual tiene sentido en cada país de Latinoamérica. La identidad, es necesaria para cada pueblo - cultura. Martín Barbero (2009), aporta señalando que:

Hasta hace muy poco, decir identidad significaba hablar de territorio y de raíces, esto es de raigambre densa, y de tiempo largo, de memoria ancestral y simbólica. De eso y solamente de eso estaba hecha la identidad. Pero decir identidad hoy, implica también -si no queremos condenarla al limbo de una tradición desconectada de las mutaciones perceptivas y expresivas del presente - hablar de redes, y de flujos, de migraciones y movilidades, de instantaneidad y desanclaje. (pp. 177, 178)

Es entonces clave, comprender que la identidad remonta al pasado, al presente y se mantiene en el futuro de acuerdo a las diferentes variables que la constituyen. Por tanto, no se puede hablar de una identidad, sino de identidades que además, va cambiando en y con el tiempo.

Según Walsh (2009) "la interculturalidad es inseparable de la identidad y la diferencia; inseparable de las maneras en las que nos identificamos con otras personas o nos diferenciamos de ella" (p.46).

Revisando ahora la relación que hay entre identidad y cultura y, entre multiculturalidad e interculturalidad, Cruz (2012), señala que en el contexto latinoamericano sobresale el debate entre multiculturalistas e interculturalistas. Si bien, tienen orientaciones diferentes, ambos conceptos no son excluyentes, comparten intereses como, la necesidad de buscar la igualdad entre las culturas y se relacionan con los contextos de pluralismo cultural, es decir, distintas culturas en los territorios.

Así Cruz (2012) señala que:

Aunque los horizontes normativos del interculturalismo son más ambiciosos, ambos enfoques presentan problemas para armonizar la igualdad entre culturas con 
el respeto por los derechos humanos. Para salvaguardar los derechos humanos, el multiculturalismo termina por instaurar una desigualdad entre culturas al aseverar que deben aceptar los principios liberales. Al amparar la igualdad entre culturas, mediante un respeto absoluto por el otro, el interculturalismo queda imposibilitado para definir los límites a la tolerancia, por lo que no define con claridad los criterios para proteger los derechos humanos. Sin embargo, dado que definir esos criterios a priori implicaría una concepción monocultural, el interculturalismo se inclina por que sea el diálogo entre culturas, mediante la hermenéutica diatópica, el medio para definirlos conjuntamente. (pp. 39-40)

El debate social debe ser profundo y, proponer, como lo hace Sartori (2001), contra argumentaciones que favorezcan un análisis crítico alejado del comunitarismo neo-romántico con un excesivo relativismo.

Todo esto con la intención de derrumbar los mitos de la modernidad y las paradojas que la tendencia universalizadora que la época genera. Lo más importante, es encontrar la peculiaridad de las culturas dentro de un universo, que marcadamente, busca la globalización. La visión Sartoriana, claramente establece diferencias entre multiculturalismo y pluralismo, considerando que el primero se contrapone al segundo y, que la multiculturalidad es una acción moduladora que diluye la diferencia constituyéndose en un vuelco, una especie de inversión de la pluralidad en su sentido más amplio y genuino. Las sociedades pueden desmembrarse y fragmentarse y la multiculturalidad, se asume como un principio antítesis y contrario a la posibilidad emancipadora que se deriva del pluralismo bien entendido.

Arfuch (2005), considera que el discurso acerca de la multiculturalidad, no puede inscribirse en el esencialismo o en la búsqueda de una esencialidad de la identidad, lo que de algún modo, denota una coherencia con Sartori (2001) en el sentido de diluir el concepto e intereses y mitos que no sólo confunden, sino que lesionan la peculiaridad de las culturas y su necesidad de configurarse autónomamente. Esto no significa desconocer, lo que García (1989) denomina el carácter multicultural de las sociedades emergentes, expresado en la policromía connatural a las comunidades diversas indígenas, afros, obreros, comerciantes, migrantes y muchas otras, que comparten un hábitat y un ecosistema de culturas en un territorio determinado. No obstante, es preciso acotar que el multiculturalismo a la manera Sartoriana, es una invitación a ir más allá de las superficialidades raciales, migratorias o lingüísticas, para enraizar el análisis y el reconocimiento de fondo de la diferencia, como presencia activa del otro, de los otros y de lo otro. Esto es básico para comprender, que las divergencias no deben asumirse de un modo trivial y esencialista, porque 
lo que en realidad representa es una riqueza plural que embellece el jardín humano, enaltece su condición existencial y reivindica los valores intrínsecos a la potencialidad que cada cultura puede manifestar cuando la sociedad en su conjunto proporciona las condiciones favorables para que éstas florezcan y se visibilicen.

Walsh (2009) reconoce la necesidad de promover relaciones positivas entre diferentes culturas, "en condiciones equitativas y en términos de igualdad" (p.41), todo ello, por encima de las diferencias de personas, grupos, tradiciones, valores y racionalidades. "En sí, la interculturalidad intenta romper con la historia hegemónica de una cultura dominante y otras subordinadas y, de esa manera, reforzar las identidades tradicionalmente excluidas para construir, tanto en la vida cotidiana como en las instituciones sociales, un con-vivir de respeto y legitimidad entre todos los grupos de la sociedad" (Walsh 2009. p.41). Se propone que la interculturalidad es una acción y una tarea de toda la sociedad.

Para Walsh (2009), multi, pluri e interculturalidad, refieren a la diversidad cultural. Constatando que, "la multiculturalidad es básicamente se refiere a la multiplicidad de culturas existentes dentro de un determinado espacio -local, regional, nacional o internacional- sin que necesariamente tengan una relación entre ellas" (p. 42). Esta concepción, se entiende como un relativismo cultural pudiendo llevar a una separación o segregación entre culturas demarcadas y cerradas sobre sí mismas. Por otro lado,

La pluriculturalidad responde a la necesidad de un concepto que represente la particularidad de la región, donde pueblos indígenas y negros han convivido por siglos (aunque conflictivamente) con blanco-mestizos, y donde los mestizajes -el cultural y el del discurso del poder- han sido, como vimos antes, parte de la realidad, conjuntamente con la resistencia e insurgencia sociocultural y, recientemente, la revitalización de las diferencias. Al contrario de la multiculturalidad, la pluriculturalidad sugiere una pluralidad histórica y actual, en la cual varias culturas conviven en un espacio territorial y juntas, supuestamente, hacen la totalidad nacional. (Walsh 2009. p. 44)

La interculturalidad, permite observar las relaciones complejas entre culturas buscando la interacción de las personas al interior de ellas. Reconociendo la existencia de asimetrías sociales y de poder, tiene la posibilidad de reconocer al otro como sujeto con identidad, diferencia y capacidades.

Desde otra perspectiva, la multiculturalidad comporta, una alta dosis de propuesta política, 
como es el caso del multiculturalismo neoliberal señalado por Londoño et al. (2018), el cual no siempre contribuye en la formación de tejido social y en la cohesión integral de las políticas públicas; por el contrario, el neoliberalismo puede incidir en la ocurrencia de lo que Sáez (2004), denomina balcanización cultural de la sociedad, aspecto que denota fundamentalmente desintegración y fragmentación de los micro universos sociales. Esta presunción desde lo político, rebate lo que García Canclini (1989), acentúa como el carácter improvisado de la cultura en el marco de las luchas políticas. Una razón válida, para comprender que el ejercicio de la multiculturalidad, debería ir más allá de estas pugnas internas en las regiones y en los países, para concretarse en una verdadera cultura sobre el quehacer político, basada en amplios y divergentes procesos de alfabetización y educación, en cuanto a la participación, la toma de decisiones y el empoderamiento cultural.

\subsection{PLURALISMO}

Para Malgesini y Giménez (2000)

El pluralismo cultural es modelo de organización social que afirma la posibilidad de convivir armoniosamente en sociedades grupos o comunidades étnica, cultural, religiosa o lingüísticamente diferentes. A diferencia de otros modelos, el pluralismo cultural valora positivamente la diversidad sociocultural y toma como punto de partida que ningún grupo tiene por qué perder su cultura o identidad propia. (p. 1)

La idea de relación entre las culturas es permanente en el tiempo así como lo son las distinciones entre ellas. La diversidad es permanente y se plantea como algo deseable y positivo y permite el fomento de la práctica de las tradiciones etnoculturales, en definitiva, que cada grupo tiene algo que ofrecer y que aprender de los otros.

Cabe hacer notar, según Rojas (1984), que el paradigma del pluralismo cultural se opone tajantemente al racismo y al asimilacionismo, pues éste acepta la presencia, coexistencia o simultaneidad de poblaciones con distintas culturas en un espacio territorial y social, ya sea en una entidad supranacional, en un Estado nación o en una nación sin Estado. Para el pluralismo cultural la diversidad cultural es positiva y enriquecedora, pues evita a toda costa homogeneizar a la sociedad; en él todas las expresiones culturales, étnicas, lingüísticas y religiosas están llamadas a formar parte de la comunidad sociopolítica para desarrollarse, sin la represión de ninguna cultura mayoritaria.

Para Martín Barbero (2009), es necesario ser reconocidos para ser tenidos en cuenta y poder tomar decisiones

Para que la pluralidad de las culturas del mundo sea políticamente tenida en cuenta es 
indispensable que la diversidad de identidades pueda ser contada, narrada. Y ello tanto en cada uno de sus idiomas como en el lenguaje multimedial que hoy los atraviesa mediante el doble movimiento de las traducciones -de lo oral a lo escrito, a lo audiovisual, a lo hipertextual- y de las hibridaciones, esto es de una interculturalidad en la que las dinámicas de la economía y la cultura-mundo movilizan no sólo la heterogeneidad de los grupos y su readecuación a las presiones de lo global sino la coexistencia al interior de una misma sociedad de códigos y relatos muy diversos, conmocionando así la experiencia que hasta ahora teníamos de identidad. (p. 178)

En Sartori (2001), el pluralismo adquiere un tono antimulticultural, no homogeneizante y con un carácter asimilacionista, mientras que para Giménez (2003) es una categoría general de la sociedad democrática y una valoración positiva de la diversidad crítica. Estas dos posturas, son pertinentes para reevaluar la concepción pluralista enmarcada en pseudocreencias que la limitan, tan sólo al respeto a la diferencia de las culturas atribuida únicamente a la periferia de sus orígenes, legados históricos y patrimonios culturales. La noción de pluralidad que se deduce del análisis es consecuente con Arnaiz y De Haro (2004), porque no pretende esconder posturas etnocéntricas ni mucho menos declarar un silencio cómplice que minimice o subvalore a los grupos más desfavorecidos. Por el contrario, se aboga por un pluralismo que admite la diversidad como un rasgo que crea identidad desde la singularidad y como un elemento, sin el cual no es posible mirar el rostro del otro para interiorizarse en su individualidad y comprender que ese ser humano es un interlocutor válido, y un complemento existencial enriquecido por la peculiaridad de matices que regeneran los universos personales que se encuentran con esta mirada desprejuiciada y libre de marquillas excluyentes.

La perspectiva, aquí planteada, es polivalente y presenta el pluralismo como un acto de reconocimiento libre y sin prejuicios que, como señalan Londoño, S; Ossa, J; Lasso, P; Castellanos, E. (2018), exigen una apertura epistemológica. Retomando a López (2013), precisa puntos de encuentro, diálogos y respeto mutuo que son valores de las sociedades que avanzan hacia la construcción de una democracia sólida. Lo epistemológico resalta la pertinencia de la educación como un proceso que abre, como una llave maestra, las puertas al conocimiento para eliminar brechas y desigualdades instaladas en una sociedad, donde el derecho a ser educado, no se garantiza en todos los sectores y grupos poblacionales. Acceder a los diferentes niveles educativos es, por lo tanto, un rasgo de madurez democrática que en el contexto del pluralismo sin barreras, se convierte en un factor que potencializa el desarrollo sostenible y contribuye en distensionar las asimétricas relaciones sociales entre los seres humanos. No es fácil recorrer un camino que aporte a la construcción plural de las identidades, pero no cabe duda que sea una tarea desafiante y 
exigente para la ciudadanía, el Estado y la institución educativa.

El pluralismo, adquiere por lo tanto, una dimensión educativa, que es muy importante para mejorar los procesos educativos y, articularlos desde una perspectiva pluricultural. Para la pluriculturalidad, implica identificación y pertinencia étnica, atención a los estilos de aprendizaje, para enriquecer el contacto y la sensibilidad social. Según Muñoz Sedano (1998), un modelo educativo basado en el pluralismo cultural, tiene en cuenta los contenidos específicos en los programas del currículo, diseña estrategias personalizadas para atender la diversidad, y genera gusto por el trabajo en la escuela, en el que la diferencia cultural es una riqueza común y no un factor de división. Esta forma de valorar y apreciar la pluralidad, es muy importante para que la institución escolar pueda verse como un jardín y no como un cuartel militar, de tal forma, que la diversidad sea un rasgo compartido y aceptado y el intercambio, una condición necesaria para que los actores escolares se comporten asertivamente en los diferentes espacios de integración y desarrollo colectivo.

\subsection{SOCIEDAD MULTIÉTNICA}

La primera referencia a lo multiétnico, remite a lo que Londoño et al. (2018) describe como vestimenta, dialectos, lenguas, costumbres, gastronomía, arqueología y riquezas históricas. Esta aproximación a los grupos raciales, en comienzo genera la necesidad de una mirada holística e integradora, en la que la raza sea mucho más que el imaginario social del indio, del afro, del inmigrante, del mestizo o del marginado.

Para Martín Barbero (2009)

El monolingüismo y la uniterritorialidad, que la primera modernización reasumió de la colonia, escondieron la densa multiculturalidad de que estaba hecha cada nación y lo arbitrario de las demarcaciones que trazaron las fronteras de lo nacional. Hoy las identidades nacionales son cada día más multilingüísticas y transterritoriales. Y se constituyen no sólo de las diferencias entre culturas desarrolladas separadamente sino mediante las desiguales apropiaciones y combinaciones que los diversos grupos hacen de elementos de distintas sociedades y de la suya propia. A la revalorización de lo local se añade el estallido de la, hasta hace poco unificada, historia nacional por el reclamo que los movimientos étnicos, raciales, regionales, de género, hacen del derecho a su propia memoria, esto es a la construcción de sus narraciones y sus imágenes. Reclamo que adquiere rasgos mucho más complejos en países en los que, como no pocos en América Latina, el Estado está aún haciéndose nación, y cuando la nación no cuenta con una presencia activa del Estado en la totalidad de su territorio. (p. 180) 
Esto es básico para entender lo planteado por Sartori (2001) con respecto a la sociedad multiétnica como modelo ejemplar para develar las implicaciones y el impacto real del pluralismo que, como dice García (1989) debe alcanzarse sin subordinar las diferencias. Esta percepción se ocupa de la fibra humana que constituye los tejidos sociales y que circula por los vasos comunicantes de la cultura, sin discriminar o estigmatizar.

En Colombia, la Constitución Política de 1991, reconoce la diversidad étnica, establece que las lenguas y dialectos de los grupos étnicos son oficiales en sus territorios. Dispone que la enseñanza impartida en comunidades con tradiciones étnicas propias, serán bilingües, garantizando la inalienabilidad, la imprescriptibilidad e inembargabilidad de sus bienes, recursos y patrimonios arqueológicos, históricos, territoriales y culturales. Este es un principio constitucional, que hoy en día se aleja de lo que se observa en la realidad de las comunidades étnicas vulnerables, que siguen sufriendo el despojo de sus tierras, el saqueo de sus riquezas y la permanente aculturización de sus creencias y costumbres. Estas son realidades manifiestas y ya, sobrediagnosticadas que ponen en escena la necesidad de construir sociedades verdaderamente multiétnicas, no sólo abiertas al reconocimiento de las minorías sino instauradas en genuinos preceptos de tolerancia y convivencia intercultural. Esto es, ni más ni menos, que propugnar por comunidades en donde los diálogos sean fértiles y fecundos para generar encuentros de identidades, acuerdos mínimos y máximos en materia de desarrollo sostenible y, ante todo, nuevos imaginarios políticos y económicos, sobre los cuales la riqueza se distribuya equitativamente y sin resaltar las asimetrías sociales.

Costa Rica, Bolivia, Ecuador, Perú, son algunos de los países latinoamericanos que tienen sociedades multiétnicas, multilingües y en varios casos, transterritoriales.

\section{LATINOAMÉRICA Y COLOMBIA ¿CONSTRUYEN SOCIEDADES MULTICULTARALISTAS, PLURIÉTNICAS Y MULTIÉTNICAS?}

El recorrido propuesto hasta ahora, establece la multiculturalidad como un concepto en construcción, el pluralismo como una noción fundamental para la disolución de barreras y fronteras, entre los seres humanos y la multietnia, en calidad de factor potenciante de los conceptos expuestos, para configurar y reconfigurar el horizonte latinoamericano y colombiano.

En este apartado, se presta atención a lo aportado por Gómez (2017) quien, sin desconocer el peso argumentativo de otros autores, ofrece una mirada particular y centrada en Latinoamérica y Colombia, para comprender mejor las nociones expuestas. Todo esto es muy importante, y aportan en la búsqueda de los antecedentes históricos y socioculturales. Porque no cabe duda, que el continente latinoamericano ha sufrido nuevos y viejos colonialismos, para reinventar una 
realidad, que está enmarcada necesariamente, en la diversidad natural, política, social y cultural, de esta parte del continente.

\subsection{EL APORTE DE PACO GÓMEZ NADAL}

El periodista español con fuertes arraigos en Latinoamérica, propone una visión alternativa del multiculturalismo en la que se destaca la vigencia de la colonialidad en tiempos de globalización, el nudo racista, la exclusión económica, política y cultural. Son para el autor aspectos que se mantienen configurados en los tiempos de hoy en día y que evidencian una significativa evocación de los tiempos coloniales. El biopoder, la obsesión cuantitativa de los censos étnicos, la acumulación capitalista, entre otros factores de lo que él denomina pueblos "sombra" se constituyen en rasgos diferenciadores de procesos históricos, sociales y económicos que demarca la trayectoria de la esclavitud, los prejuicios y la exclusión en países como Ecuador, Colombia, Panamá, Guyana Francesa y otros que Gómez (2017) retrata en sus líneas históricas, literarias y antropológicas, en una crónica escueta y sin tapujos.

La contribución de Gómez (2017) es directa, y pone el dedo en la llaga porque determina claramente los mecanismos de dominación, de control de la población, los dispositivos implementados para la dislocación cultural de los pueblos indígenas y afros, lo mismo que los artefactos de asimilación cultural generados por el discurso del opresor que frenan la construcción de un relato indígena propio. La lógica mercantilista del capitalismo, del poder imperialista, del blanqueo intelectual y social de las élites criollas formadas en las universidades europeas o yanquis, sustituyen la lógica del "pancoger" y las cosmovisiones propias instaladas en los imaginarios de los embera, cunas, witotos y otros grupos de tradición indigenista. Latinoamérica como sociedad multiétnica, según Gómez (2017), ha sufrido una forzada adecuación al modelo económico capitalista, basado en el poder del dinero, que fractura la gestión autónoma del tiempo y del espacio y reemplaza un modelo de convivencia basado en la confianza, la colaboración, la reciprocidad y el trabajo comunitario, pilares de las culturas de estos pueblos.

Sin redundancias diagnósticas, Gómez (2017) desnuda la realidad de los pueblos indígenas en Latinoamérica y, de qué manera lenta y sistemáticamente, estos pueblos se alejan de su paideia educativa aprendida de los bosques, de los ríos, de las selvas, de sus tradiciones curativas y de todo lo que vibra en sus cosmogonías ancestrales. Mientras tanto la vida continúa y el flujo de la realidad indígena se retrasa deliberadamente, las nuevas colonias y favelas satelitales se erigen en medio de una sociedad moderna que continúa paralizada y sin actuar en defensa de los que estaban aquí antes de la llegada de los opresores. Sin imprimir sellos o tintes ideológicos o partidistas, queda claro que desde el punto de vista social, económico, político y cultural, los llamados pueblos 
“sombra” por Gómez (2017), están encerrados por el hombre blanco, incluyendo en esta categoría a todos los seres humanos que no logran sensibilizarse y conmoverse, ante un triste espectáculo casi apocalíptico que sin exageraciones drásticas, pueden conducir a la desaparición de un pueblo con historia y con pasado, pero desarraigado, sin presente y sin futuro.

\subsection{ANÁLISIS DESDE LA REALIDAD COLOMBIANA}

El país colombiano, está afrontando evidentes tendencias hacia el multiculturalismo. La pluralidad, y la configuración multiétnica de su entramado social. Se están dando pasos lentos, y de acuerdo a las capacidades y potencialidades culturales, pueden desplegarse, en el contexto de los acontecimientos históricos, políticos, sociales, e incluso educativos de la nación. La gradualidad de estos avances, contrasta a veces, con la lentitud de las apropiaciones gubernamentales, ciudadanas y éticas, que se encuentran instaladas en los imaginarios colectivos, que deben restaurarse, y poner en marcha, con el propósito de buscar nuevos florecimientos, de las acciones multiculturales y pluralistas, de tal forma, que sea posible, una sociedad colombiana democrática, equitativa, solidaria y que le brinde acogida a todos los ciudadanos.

Colombia requiere con urgencia, lo que Gómez (2017) denomina indigenizar la modernidad, construir un nuevo proyecto político, económico y racial incluyente en el cual las concesiones madereras, mineras y petrolíferas, no se entreguen a las multinacionales que de manera voraz y despiadada arrasan con los ecosistemas y destruyen el patrimonio simbólico, cultural y social no sólo de los pueblos indígenas sino de los afros y mestizos que aún ocupan territorios ancestrales en la Guajira, los Llanos Orientales, los manglares del Pacífico y las regiones Amazónicas fronterizas con Brasil y con Perú. Incluso en la zona Andina colombiana, los Santanderes, los departamentos de Nariño y del Cauca, hay destellos de pueblos indígenas que se resisten a desaparecer en esta hojarasca de pseudo progreso y civilización cuyo único resultado ha sido replegar nuevas formas de despojo, explotación y usurpación.

A pesar de todas estas contingencias, Colombia es un paisaje humano diverso y policromático, en sus montañas, valles, llanuras y litorales todavía se percibe el aroma de la presencia indígena, afro, raizal y rom (gitanos). El perfume de pueblos Wayuu, Kogui, Katíos, Cunas y Witotos, se mezcla con las humanas esencias de los afros del Chocó y del norte del Cauca, lo mismo que con el olor a tierra fecunda que se desprende del campesino del eje cafetero, del altiplano Cundiboyacense y la prolífica Costa Caribe. Los ritmos musicales del bambuco, la cumbia, el mapalé, la puya vallenata, la salsa valluna y el calipso sanandresano, se mezclan en un paisaje sonoro, que continúa alimentando la esperanza de un país que en medio de la devastación sigue siendo feliz y optimista. 
En la práctica Colombia es una sociedad multiétnica, pluralista y multicultural que se resiste a los neocolonialismos y que todavía conserva la ilusión de reconocer en su diversidad la mayor de sus riquezas.

\section{CONSIDERACIONES FINALES}

Afirmar que los pueblos indígenas, afros, raizales y rom (gitanos) en Colombia y en Latinoamérica son excluidos, explotados y marginados es, en comienzo, una redundancia histórica y una especie de cacofonía lingüística en su sentido más amplio. No obstante, la redundancia hecha en este ensayo, lo que pretende es crear una resonancia que suscite un análisis crítico de lo que esto implica en la construcción de un concepto de multiculturalidad, menos asociado a los discursos hegemónicos y más cercano a las realidades concretas de pueblos que están luchando por no morir en el desierto estéril de las sociedades postmodernas. El neocolonialismo expresado en el despojo simbólico y cultural, es hoy en día, el mayor enemigo del pluralismo como concepto que debe instalarse en las raíces profundas de grupos y comunidades en las que la diversidad es el rasgo característico.

Los aportes teóricos de Sartori (2001), Gómez (2017), de Walsh (2009) y de Martín Barbero (2009), son iluminadores para comprender que el multiculturalismo puede, en determinado momento, desconocer la pluralidad y, que el mayor enemigo de los pueblos indígenas, afros y mestizos no es la modernidad sino la mano destructora del hombre blanco. Entiéndase por blanco, al ser humano sin conciencia histórica y carente de la capacidad para mirar a los ojos de las personas que representan estas comunidades y expresarles un respeto mínimo por su identidad y estatuto ontológico en un mundo cada vez más excluyente y globalizador.

A pesar de estas circunstancias sociales, económicas, políticas y culturales poco deseables, en Colombia la multidiversidad étnica, el pluralismo y la policromía de su población, son peculiaridades de un retrato humano que muestra en cada una de las regiones del país una inagotable riqueza natural, cosmogónica, simbólica, musical, histórica, tradicional y expresiva. Esta Nación, es un mosaico vital que se robustece mediante la circulación fluyente de valores, costumbres y tradiciones que circulan en los vasos comunicantes de una cultura que tozudamente se niega a desaparecer.

Es indudable, que Latinoamérica y Colombia, muestran una realidad similar, en materia de multiculturalismo, pluralismo y multietnia. En ésta, la característica común ha sido, la explotación, la confrontación, el abuso, el apropio de riquezas y territorios, entre otros aspectos, que deben superarse, con el fin de emancipar a los pueblos y liberar en ellos, el poder de transformar el estado actual de los acontecimientos. Hay que poner en marcha una multiculturalidad, basada en 
la pluralidad diferenciadora y no en la homogeneidad aplastante; es pertinente y necesario, que los pueblos indígenas accedan a oportunidades jurídicas, sociales y educativas $\mathrm{y}$, más que todo, logren restituir sus valores ancestrales y reverdecer sus patrimonios históricos. Todo esto en el marco de la lucha por sus derechos, territorios y lugares de preservación cultural, sin que esto se inscriba solamente en los campos discursivos, o en la falsa retórica derivada de los modelos populistas de gobierno.

La perspectiva intercultural abre a la posibilidad de terminar con la exclusión social de personas, grupos y culturas. Desde el pluralismo cultural, la idea de similitud y diferencia, están siempre presente como una posibilidad y necesidad entre los pueblos y culturas. Es el momento en que los Estados y Gobiernos actúen políticamente considerando que todas las culturas aportan al desarrollo de las naciones.

\section{REFERENCIAS BIBLIOGRÁFICAS}

Arfuch, L. (2002). Identidades, sujetos y subjetividades: Identidades, sujetos y subjetividades. Buenos Aires: Carol-Go SA

Arnaiz, P. y De Haro, R. (2004). Ciudadanía e Interculturalidad: claves para la educación del siglo XXI. Murcia: Revista Educatio siglo XXI22, 19-37. Recuperado de https://revistas.um.es/ educatio/article/view/97

Constitución Política de Colombia (1991)

García Canclini, N. (1989). Culturas híbridas. Estrategias para entrar y salir de la modernidad. México: Grijalbo.

Giménez, C. (2003). Pluralismo, multiculturalismo e interculturalidad. Propuestas de clarificación y apuntes educativos. Madrid: Edebé.

Gómez Nadal, Paco (2017). Indios, negros y otros indeseables. Capitalismo, racismo y exclusión en América Latina y el Caribe. Ecuador: AVYA YALA.

González, P. (2009) Las étnicas coloniales y el Estado Multiétnico. En De la sociología del poder a la sociología de la explotación: pensar América Latina en el siglo XXI. Pp. 293-309 Recuperado de http://biblioteca.clacso.edu.ar/clacso/coediciones/20150113025424/16.pdf 
Londoño, S; Ossa, J; Lasso, P; Castellanos, E. (2018). Diálogos Interculturales Latinoamericanos: Hacia una educación superior intercultural. Cali: Universidad de San Buenaventura. Recuperado de file: Interculturalidades_en_disputa_Ideologia.pdf

López, José Luis (2013). Diversidad cultural y educación intercultural. Melilla: GEEPP.

Malgesini, G; Giménez, C. (2000). Pluralismo Cultural. Recuperado de http://courseware. url.edu.gt/PROFASR/Estudiantes/Facultad\%20de\%20Ciencias\%20Pol\%C3\%ADticas\%20 y\%20Sociales/Poder\%20y\%20Pluriculturalidad\%20Social\%20en\%20Guatemala/Textos\%20 te\%C3\%B3ricos\%20de\%20apoyo/Malgesini-Gim\%C3\%A9nez,\%20Pluralismo\%20Cultural.pdf

Martín Barbero, J. (2009). Culturas y Comunicación Globalizada. AI/C - Revista Científica de Información y Comunicación 2009, 6, pp175-192

Muñoz, A (1998). Hacia una educación multicultural: Enfoques y modelos. Revista Complutense de Educación IS5N: 1130-2496 1998, vol. 9, ni 2:101-135. Universidad Complutense de Madrid.

Rojas, I. (s/f) Pluralismo cultural, multiculturalismo e interculturalidad. Recuperado de https://www.cultura.gob.mx/turismocultural/cuadernos/pdf13/articulo17.pdf

Sartori, G. (2001). La Sociedad Multiétnica, Pluralismo, Multiculturalismo y Extranjeros. Madrid: Editorial Taurus. Recuperado de http://www.esi2.us.es/ mbilbao/pdffiles/sartori1.pdf

Sáez, R. (2004). La educación intercultural. Revista de Educación. Vol. 339, pp. 859-881. Madrid: Gobierno de España

Stavenhagen, R. (s/f). Identidad indígena y multiculturalidad en América Latina. Recuperado de file: Dialnet-IdentidadIndigenaYMulticulturalidadEnAmericaLatina-1047379.pdf

Walsh, C. (2009). Interculturalidad, Estado, Sociedad. Luchas (de) coloniales de nuestra época. Quito: Universidad Andina Simón Bolívar y Abya Yala. 